\title{
Is HIV/AIDS in Africa distinct? What can we learn from an analysis of the literature?
}

\author{
OMWOYO BOSIRE ONYANCHA, ${ }^{\mathrm{a}}$ DENNIS N. OCHOLLA ${ }^{\mathrm{b}}$ \\ ${ }^{a}$ University of South Africa, Department of Information Science, P.O. Box 392 UNISA 0003, South Africa \\ ${ }^{\mathrm{b}}$ University of Zululand, Department of Library and Information Science, \\ Private Bag x1001, KwaDlangezwa 3886, South Africa
}

\begin{abstract}
This paper investigates, through an analysis of the published literature, the notion held by several people that HIV/AIDS in Africa is unique. Using co-word and multidimensional scaling (MDS) analyses of MEDLINE-extracted HIV/AIDS records, this study used five lists of terms to investigate the related-ness of various factors and diseases to HIV/AIDS. The lists consisted of risk factors, sexually transmitted diseases, tropical diseases, opportunistic diseases, and pre-disposing factors. Data (i.e. words.txt - consisting of keywords/phrases describing the aforementioned factors and diseases; and text.txt - containing HIV/AIDS papers' titles) were analyzed using TI computer-aided application software, developed by Leydesdorff. Results revealed that several factors and diseases that are pre-dominant in Sub-Saharan Africa exhibited strong and high pattern of co-occurrences with HIV/AIDS, implying close associated-ness with the epidemic in the region. Further areas of research, whose results will be used to make conclusive observations and arguments concerning the uniqueness of HIV/AIDS in Sub-Saharan Africa, are recommended.
\end{abstract}

\section{Introduction}

In a letter written by Thabo Mbeki in 2000 to world leaders, the South African president, observed that "it is obvious that whatever lessons we have to, and may draw from, the West about the grave issue of HIV/AIDS, a simple superimposition of Western experience on African reality would be absurd and illogical" (as cited in [COHEN, 2000]). Not only do the manifestations of the AIDS disease in Africa differ from those in the West but, as COHEN [2000] observes, AIDS-related diseases, and possibly disease progression itself, differ in the continent (i.e from region to region) that is home to about $71 \%$ of the global population infected with HIV. In turn, this difference is said to be clinical. Cohen reports that while tuberculosis amongst AIDS patients is rare in the west - especially, the USA and Europe - it is the most common disease afflicting HIV-positive people in Africa. He further notes that Kaposi's Sarcoma, a cancer that causes purple skin blotching, commonly afflicts both HIV uninfected and infected persons in Africa, while in industrialized nations, the disease is largely restricted to HIV-infected gay men. The same applies to pneumocysts carinii, a

Received December 5, 2007

Address for correspondence:

OMWOYO BOSIRE ONYANCHA

E-mail: b_onyancha@yahoo.com

0138-9130/US \$20.00

Copyright (C) 2008 Akadémiai Kiadó, Budapest

All rights reserved 
strain of pneumonia predominant in HIV-infected persons in developed countries. These arguments are based on clinical diagnoses of various diseases in HIV infected persons. Further observations point to how various factors aggravate the spread of HIV/AIDS in developing countries, hence the argument that the impact of HIV/AIDS in these countries is different from that felt in developed countries.

But what can we learn from an analysis of published literature on HIV/AIDS? Which of these known diseases/infections and factors are most commonly associated with HIV/AIDS in Africa? Given that scientific research is often mirrored in published literature, is the above description of the uniqueness of HIV/AIDS in Africa reflected in published literature? These questions reflect the aim of this study, namely, to find out whether or not HIV/AIDS in Africa is a distinct disease by identifying the opportunistic infections, pre-disposing factors, risk factors, sexually transmitted diseases, and other tropical diseases most commonly associated with HIV/AIDS in Africa as a whole, and Eastern and Southern Africa in particular. At this stage, the study provides the preliminary findings of a broader content analysis study of HIV/AIDS literature as produced in or about Africa.

\section{Methods and procedures}

\section{The method}

Co-word analysis was employed to examine the relatedness of HIV/AIDS-specific terms to five groups of terms outlined in the previous paragraph.Co-Word analysis is a content analysis technique that "reveals patterns and trends in technical discourse by measuring the association strengths of terms representative of relevant publications or other texts produced in a technical field" [COULTER \& AL., $1998: 1206$ ]. The method is meant to identify associations between publication descriptors in order to determine themes and trends in a discipline [KOSTOFF, 2001]. Co-word analysis provides a set of terms or descriptors that not only regularly occur together in a text or record, but also [may be used to] measure the regularity with which events occur [JACOBS, 2002]. Thus, the process "measures the strength of association between two or more documents by the co-occurrence of the same 'words' (phrases, descriptors, classification codes, etc) in a chosen field". Contextually, the term 'documents' is used to refer to publications/records or the titles, abstracts, and/or descriptors of a record [CALLON \& AL In: SCHNEIDER \& BORLUND, 2004 : 537]. 
This method has been extensively used, as illustrated and exemplified in its published literature [CALLON \& AL., 1986; LEYDESDORFF, 1988; TURNER \& AL., 1988; COURTial \& LAW, 1989; WhitTaKer, 1989; CALlON \& AL., 1991; LAW \& WhitTAKer, 1992; COURTIAL, 1994; COULTER \& AL., 1998; KopCSA \& SCHIEBel, 1998; BoOKSTEIN \& RAITA, 2001; Ding \& AL., 2001; JACOBS, 2002; KRSUL, 2002; AIZAWA \& KAGEURA, 2003; BALDWIN \& AL., 2003; BOOKSTEIN \& AL., 2003; SCHNEIDER \& BORLUND, 2003; HUI \& FONG, 2004; ONYANCHA \& OCHOLLA, 2005]. The different approaches and ways that co-word analysis has been applied in a variety of studies confirms LEYSDEDORFF's [1988 : 209] observation that "since most science studies and nearly all science policy studies use institutionally defined sets of documents, this instrument [co-word analysis] could have a wide range of applications".

The co-word analysis technique has been most commonly utilized in mapping or tracing patterns and trends in term associated-ness. Most of the aforementioned studies fall in this category. We briefly provide a glimpse of the applicability of co-word analysis by reviewing a few of the studies that have used the method, beginning with AIZAWA \& KAGEURA [2003] who used the technique to calculate the association between technical terms based on co-occurrences in keyword lists of academic papers. The technique was also employed by Baldwin, Hughes, Hope, Jacoby \& Ziebland (2003), who mapped ethics and dementia literature in order to identify dominating ethical issues, new and emerging areas of interest and those areas triggered by external events such as legal cases. ONYANCHA \& OCHOLLA [2005] used co-word analysis to measure the relatedness of opportunistic infections to HIV/AIDS. Further examples of applications include: KOSTOFF [2001], who used the method to identify research themes in software engineering that (1) remained constant (2) matured and diminished as major research topics and (3) emerged as predominant research topics throughout the period of study; Jacobs (2002), who employed co-word analysis to study the use of particular words to describe respondents' job functions and the citation of information sources; and SCHNEIDER \& BORLUND [2004], who considered the applicability of co-word analysis in the construction and maintenance of thesauri. Citing several authors, SCHNEIDER \& BORLUND [2004 : 537] noted that the "units of analysis connected to coword analysis (i.e. words, phrases, and descriptors) may illustrate cognitive structures of a field when displayed in so-called 'semantic maps'”.

Table 1. List of countries and regions used in downloading papers from MEDLINE, SCI and SSCI

\begin{tabular}{lllll}
\hline Angola & Botswana & Djibouti & Eritrea & Ethiopia \\
Kenya & Lesotho & Malawi & Mozambique & Namibia \\
Somalia & South Africa & Sudan & Swaziland & Tanzania \\
Uganda & Zambia & Zimbabwe & Eastern Africa & Africa, East* \\
Southern Africa & Africa, South* & & & \\
\hline
\end{tabular}


ONYANCHA \& OCHOLLA: Is HIV/AIDS in Africa distinct?

Table 2. List of terms used to identify HIV/AIDS papers from MEDLINE, SCI and SSCI

\begin{tabular}{|c|c|c|c|c|}
\hline $\begin{array}{l}\text { Acquired } \\
\text { Immunodeficiency } \\
\text { Syndrome }\end{array}$ & $\begin{array}{l}\text { Immunodeficiency } \\
\text { syndrome, } \\
\text { Acquired }\end{array}$ & $\begin{array}{l}\text { Immunologic } \\
\text { Deficiency } \\
\text { Syndrome, } \\
\text { Acquired }\end{array}$ & $\begin{array}{l}\text { Acquired Immune } \\
\text { Deficiency } \\
\text { Syndrome }\end{array}$ & $\begin{array}{l}\text { Pneumonia, } \\
\text { Pneumocystis } \\
\text { Carinii }\end{array}$ \\
\hline $\begin{array}{l}\text { AIDS Arteritis, } \\
\text { Central Nervous } \\
\text { System }\end{array}$ & $\begin{array}{l}\text { AIDS Dementia } \\
\text { Complex }\end{array}$ & $\begin{array}{l}\text { AIDS } \\
\text { Seropositivity }\end{array}$ & $\begin{array}{l}\text { HIV } \\
\text { Seroprevalence }\end{array}$ & $\begin{array}{l}\text { Immunologic } \\
\text { Deficiency } \\
\text { Syndromes }\end{array}$ \\
\hline $\mathrm{HIV}^{*}$ & HTLV-III & LAV-HTLV-III & Receptors, HIV & $\begin{array}{l}\text { mmunoblastic } \\
\text { Lymphadenopathy }\end{array}$ \\
\hline $\begin{array}{l}\text { Human T-Cell } \\
\text { Lymphotropic Virus } \\
\text { Type III }\end{array}$ & Sarcoma, Kaposi’s & $\begin{array}{l}\text { Human } \\
\text { Immunodeficiency } \\
\text { Virus }\end{array}$ & $\begin{array}{l}\text { AIDS related } \\
\text { complex }\end{array}$ & $\begin{array}{l}\text { Human T } \\
\text { Lymphotropic } \\
\text { Virus Type III }\end{array}$ \\
\hline $\begin{array}{l}\text { Cytomegalic } \\
\text { Inclusion Disease }\end{array}$ & $\begin{array}{l}\text { Immunodeficiency } \\
\text { Virus, Human }\end{array}$ & $\begin{array}{l}\text { Virus, Human } \\
\text { Immunodeficiency }\end{array}$ & $\begin{array}{l}\text { Viruses, Human } \\
\text { Immunodeficiency }\end{array}$ & $\begin{array}{l}\text { Reverse } \\
\text { Transcriptase } \\
\text { Inhibitors }\end{array}$ \\
\hline $\begin{array}{l}\text { Human T-Cell } \\
\text { Leukemia Virus }\end{array}$ & & & & \\
\hline
\end{tabular}

\section{Data analysis and presentation procedures}

The MEDLINE database was used to extract relevant data on HIV/AIDS research in Eastern and Southern Africa. Two sets of terms (i.e. HIV/AIDS-specific terms and country terms) were generated using several published sources. Tables 1 and 2 provide the terms used to download HIV/AIDS papers from the MEDLINE database. An advanced search mode was used to search and download data using the Title (TI), Author's Address (AF), Subject (SU) and Abstract (AB) fields. A total of 6476 records were downloaded, and upon screening (removal of irrelevant and duplicate records), 6178 records were obtained and analyzed. In order to find out the uniqueness of HIV/AIDS in Africa five aspects were considered as outlined on page one.

Five lists of these diseases and factors were initially drawn from our personal experience with their usage in literature. Several sources (e.g. ([ORDBERG, 2001; CONLON \& SNYDMAN, 2004]) were thereafter used to refine the lists. Finally, expert advice was sought from a resident medical doctor and lecturers in the Departments of Nursing (University of Eastern Africa, Baraton and University of Zululand, respectively) who advised us on the terms that needed to be dropped from, or added to the lists. Extreme caution was taken to ensure that the lists were as exhaustive as possible. Two computer files were prepared, namely, words.txt (containing the words/names in Appendix A) and text.txt (containing titles of HIV/AIDS records) for analysis. Various authors (e.g. Luhn, Feinberg, Buxton, Manten, and Tocatlian, all as cited by [YITZHAKI, $2001:$ 759]) have noted that titles are very important components of any scientific or scholarly article as they form part of the access points in search and 
retrieval processes. According to YITZHAKI [2001: 759], many information retrieval systems "depend heavily on indexing by automated, computerized selection of words from article titles". Perhaps this is why great importance is placed on highly informative titles and it was on this basis that we considered the title words for a coword analysis.

Data (i.e. contained in words.txt and text.txt) were analyzed using TI.exe computer application software, developed by Prof. Leysdedorff, University of Amsterdam. The co-occurrence files thus generated (i.e. COOCC.DBF and COSINE.DBF) were exported to UCINET for the preparation of computer files that could be used to visualize the inter-relationships (see Figures 1-5) as well as to conduct a non-metric multidimensional scaling analysis whose scatter graphs are provided as Figures 6-9 which show the associated-ness of HIV/AIDS with each of the variables (i.e. words/names). Notable in Figures $1-5$ is the heaviness of some of the lines joining a pair of terms, implying stronger ties between the terms. We excluded Figure 10 (which was meant to provide a MDS mapping of the inter-relationships between HIV/AIDS and other diseases) because it was not legible. We chose to use the COSINE.DBF file to conduct the MDS analysis because it consisted of normalized counts unlike the COOCC.DBF file which contained raw co-occurrence counts. The maps generated using the normalized counts normally depict relationships among the entities (i.e. individuals, institutions, word occurrences, etc) better. MDS mapping finds a set of points in k-dimensional space in such a way that the Euclidean distances among these points correspond as closely as possible to a rank preserving transformation of the input proximities. In the analysis of the similarities between the items analyzed, the program draws a set of the items close together on the MDS map BORGATTI \& AL. [2002]. The same approach was adopted by VAUGHAN \& YOU [2006]. LEYDESDORFF [2004] explains that coocc. $d b f$ contains a co-occurrence matrix of the words found in the texts. In turn, this matrix is symmetrical and contains the words both as variables and as labels in the first field. The main diagonal is set to zero. The number of co-occurrences is equal to the multiplication of occurrences in each of the texts. Cosine. $d b f$ contains a normalized co-occurrence matrix of the words from the same data. Normalization is based on the cosine between the variables conceptualized as vectors (Salton \& McGill as cited by [LEYSDERDORFF, 2004]).

Both files (coocc.dbf and cosine.dat) contain the information in DL-format. Whereas the file coocc.dbf consists of co-occurrence frequencies, cosine.dat contains the strengths of ties between two or more words in the text, in which case the value ranges between zero and one whereby the higher the value, the stronger the relationship between the words. Finally, the findings from the above three analyses were compared with results from previously conducted international and foreign studies in order to determine whether or not there were differences that would warrant a generalized conclusion illustrating that HIV/AIDS in Africa is distinct. 


\section{Results}

The results are presented under five sub-headings namely: co-occurrence of HIVAIDS with opportunistic diseases; co-occurrence of HIV/AIDS with pre-disposing factors; co-occurrence of HIV/AIDS with risk factors; co-occurrence of HIV/AIDS with other sexually transmitted diseases; and co-occurrence of HIV/AIDS with other tropical diseases.

\section{Co-occurrence of HIV/AIDS with opportunistic diseases}

Figure 1 reveals that AIDS co-occurred with 16 opportunistic infections (OIs) as follows: Kaposi's sarcoma (16, $\boldsymbol{S}=0.04)$, Tuberculosis $(16, \boldsymbol{S}=0.02)$, Cancer $(7, \boldsymbol{S}=0.03)$, Mycobacterium Avium Complex (3, $\boldsymbol{S}=0.01)$, Pneumocystis Carinii (2, $\boldsymbol{S}=0.01$ ), Pneumonia (2, $\boldsymbol{S}=0.01$ ), Salmonella (2, $\boldsymbol{S}=0.02)$, Cryptococcosis (1, $\boldsymbol{S}=0.02)$, Cytomegalovirus (1, $\boldsymbol{S}=0.01), \quad$ Leukoencephalopathy $(1, \quad \boldsymbol{S}=0.02), \quad$ Lymphoma (1, $\boldsymbol{S}=0.01)$, PML (1, $\boldsymbol{S}=0.01)$, Streptococcus pneumoniae (1, $\boldsymbol{S}=0.01)$, and Varicella Zoster (1, $\boldsymbol{S}=0.02)$. HIV co-occurred with 19 terms, with the highest co-occurrences originating from Tuberculosis (198, $\boldsymbol{S}=0.17$ ), Pneumonia (23, $\boldsymbol{S}=0.06)$, Mycobacterium Avium Complex $(18, \boldsymbol{S}=0.05)$, Candidiasis $(17, \boldsymbol{S}=0.03)$, Kaposi's sarcoma (16, $\boldsymbol{S}=0.03)$, and Herpes Simplex $(10, \boldsymbol{S}=0.03)$. Others were Pneumocystis carinii (9, $\boldsymbol{S}=0.03)$, Carcinoma (4, $\boldsymbol{S}=0.02)$, Lymphoma (3, $\boldsymbol{S}=0.01)$, Salmonella $(3, \boldsymbol{S}=0.02)$, Streptococcus pneumoniae (3, $\boldsymbol{S}=0.01)$, Kansasii (2, $\boldsymbol{S}=0.02)$, Cryptosporidiosis (1, $\boldsymbol{S}=0.01)$, Cytomegalovirus (1, $\boldsymbol{S}=0.01)$, Histoplasmosis (1, $\boldsymbol{S}=0.01)$, Staphylococcus pneumoniae (1, $\boldsymbol{S}=0.02)$, and Varicella Zoster $(1, \boldsymbol{S}=0.01)$.

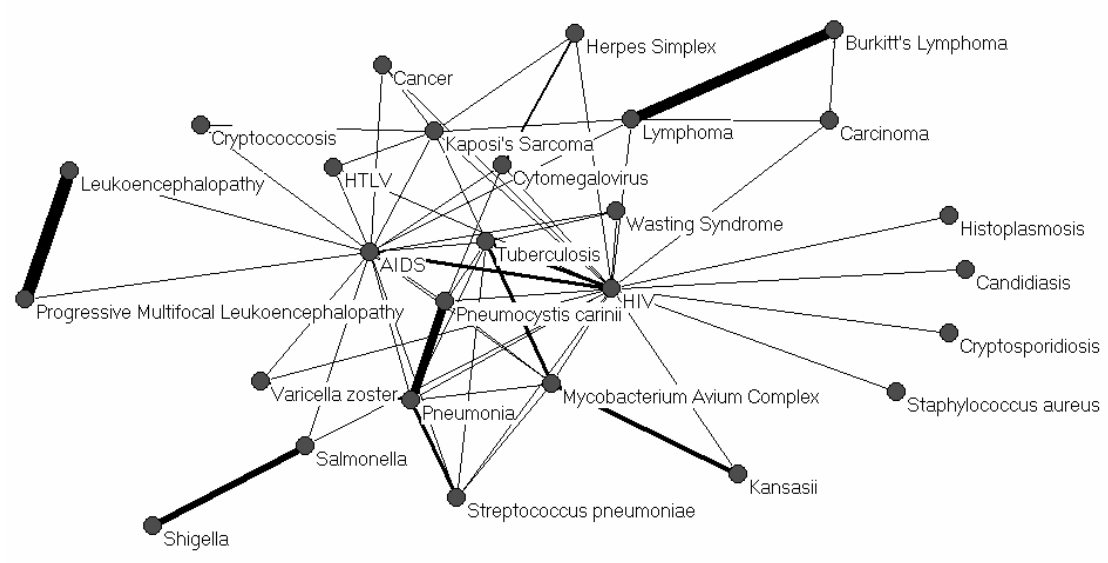

Figure 1. Normalized co-occurrence of HIV/AIDS and opportunistic infections 
Concerning the occurrence of HIV/AIDS with pre-disposing factors, it was found that there were several co-occurrences of AIDS, HIV and HTLV and most of the predisposing factors, implying that some of these factors may be playing a role in the spread of HIV/AIDS (see Figure 2). These include Drug Abuse, which co-occurred with AIDS in 51 titles and produced a normalized co-occurrence of $S=0.10$, followed by Rural-related factors (41, $\boldsymbol{S}=0.06$ ), Orphans (27, $S=0.10$ ), Gender ( $9, S=0.04)$, Poverty ( $8, S=0.05)$, and War $(8, S=0.06)$. Other terms that co-occurred with AIDS are Culture (3, $\boldsymbol{S}=0.02$ ), Refugees (3, $\boldsymbol{S}=0.02$ ), Violence (3, $\boldsymbol{S}=0.02$ ), Discrimination (2, $\boldsymbol{S}=0.02$ ), Labor Migration (2, $\boldsymbol{S}=0.03)$, and Rape $(2, \boldsymbol{S}=0.01)$. The rest produced one cooccurrence each.

HIV co-occurred with rural-related issues $213(\boldsymbol{S}=0.21)$ times, followed by drug abuse (51, $\boldsymbol{S}=0.07$ ), gender (20, $\boldsymbol{S}=0.07$ ), violence (11, $\boldsymbol{S}=0.05$ ), and socioeconomic factors $(7, S=0.05$ ), while orphans, poverty, rape and refugees produced 6 cooccurrences each. Of the 32 pre-disposing factors, 11 terms did not co-appear with any other term. These were: Primitivity, Illiteracy, Unemployment, Sanitation, Handicapped, Uneducated, Disability, Urbanization, Conflict, Under-development (or underdeveloped), and Marginalization.

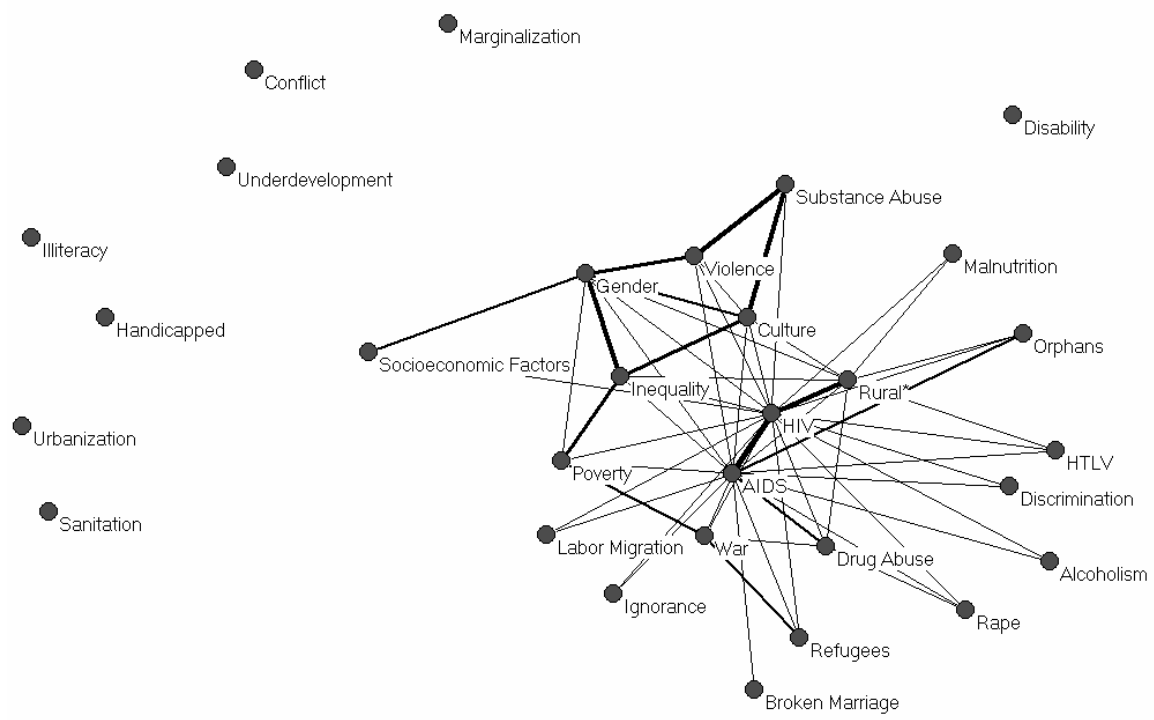

Figure 2. Normalized co-occurrence of HIV/AIDS and pre-disposing factors 
ONYANCHA \& OCHOLLA: Is HIV/AIDS in Africa distinct?

\section{Co-occurrence with risk factors}

Six descriptors did not have any co-occurrence links with HIV/AIDS terms as shown in Figure 3. These consisted of Adultery, Heterosexuality, homosexuality, Gonorrhea, Needlestick injury, and Promiscuity. It was noted that AIDS had cooccurred with 20 terms, in the descending order (measured by co-occurrence frequencies): Sexual Intercourse (40, $S=0.08$ ), Drug Abuse (51, $S=0.10$ ), Condom Attitudes (19, $\boldsymbol{S}=0.04)$, Infected Mothers (10, $\boldsymbol{S}=0.01)$, Sexually Transmitted Diseases ( $9, \boldsymbol{S}=0.02$ ), and Non-usage of Condoms ( $8, \boldsymbol{S}=0.03$ ), to mention a few. HIV had its highest frequency of co-occurrence with Infected Mothers (303, $S=0.26$ ), followed by Mother-to-Infant Transmission $(128, \boldsymbol{S}=0.17)$, Sexual Intercourse $(80, \boldsymbol{S}=0.11)$, Sexually Transmitted Diseases (78, $S=0.11$ ), Blood Transfusion (75, $S=0.11$ ), and Drug Abuse (51, $S=0.07)$. Others that recorded high frequencies of co-occurrence with HIV were Oral Sex (34, $\boldsymbol{S}=0.08)$, Breastfeeding (28, $\boldsymbol{S}=0.08$ ), Genital Herpes (26, $\boldsymbol{S}=0.06$ ), Circumcision (23, $S=0.07$ ), Non-Usage of Condoms (22, $S=0.06$ ), Condom Attitudes (21, $\boldsymbol{S}=0.03$ ), Syphilis (21, $\boldsymbol{S}=0.06$ ), Bacterial Vaginosis (15, $\boldsymbol{S}=0.06$ ) and Milk $(11, S=0.04)$. HTLV co-occurred once [each] with Breastfeeding, Homosexuality, NonUsage of Condoms, and Sexually Transmitted Diseases.

\section{Co-occurrence with other sexually transmitted diseases (STDs)}

Co-occurrence of HIV/AIDS and other sexually transmitted diseases (see Figure 4) reveals that there were terms that did not co-appear with any of the three HIV/AIDS terms in the titles. These include Condylomata Acuminata, Gonorrhea, Lyphogranuloma Venereum, Molluscum Contagiosum, Pediculosis Pubis, Pubic Lice, Scabies and Trichomonal Vaginalis. Results revealed that the term "AIDS" co-occurred with Human Papillomavirus Infection in $13(\boldsymbol{S}=0.03)$ titles, while it co-appeared with the descriptor "Sexually Transmitted Diseases" $9(\boldsymbol{S}=0.02)$ times. Other co-occurrences involved Hepatitis B (7, $\boldsymbol{S}=0.02)$, Syphilis ( $3, \boldsymbol{S}=0.01$ ), Bacterial Vaginosis $(1, \boldsymbol{S}=0.01$ ) and Genital Warts (1, $\boldsymbol{S}=0.003$ ). HIV had more co-occurrences than AIDS, results that coincide with all the other analyses. It recorded the highest frequency with Human Papillomavirus Infection (144, $S=0.09)$ followed by Sexually Transmitted Diseases (78, $S=0.11)$, Genital Warts $(26, S=0.06)$, Hepatitis B (21, $\boldsymbol{S}=0.04)$, Syphilis (21, $\boldsymbol{S}=0.06$ ), Bacterial Vaginosis (15, $\boldsymbol{S}=0.06$ ), Herpes Zoster (10, $\boldsymbol{S}=0.04)$, Candidiasis (4, $\boldsymbol{S}=0.03$ ), Granuloma Inguinale (3, $\boldsymbol{S}=0.03$ ), Chlamydia (2, $\boldsymbol{S}=0.01)$, Pelvic Inflammatory Diseases $(2, S=0.01)$, and Trichomoniasis $(1, S=0.01)$. There were two terms that co-occurred with HTLV, notably, Human Papillomavirus Infection (3, $\boldsymbol{S}=0.02)$ and Sexually Transmitted Diseases $(1, \boldsymbol{S}=0.02)$. 
ONYANCHA \& OCHOLLA: Is HIV/AIDS in Africa distinct?

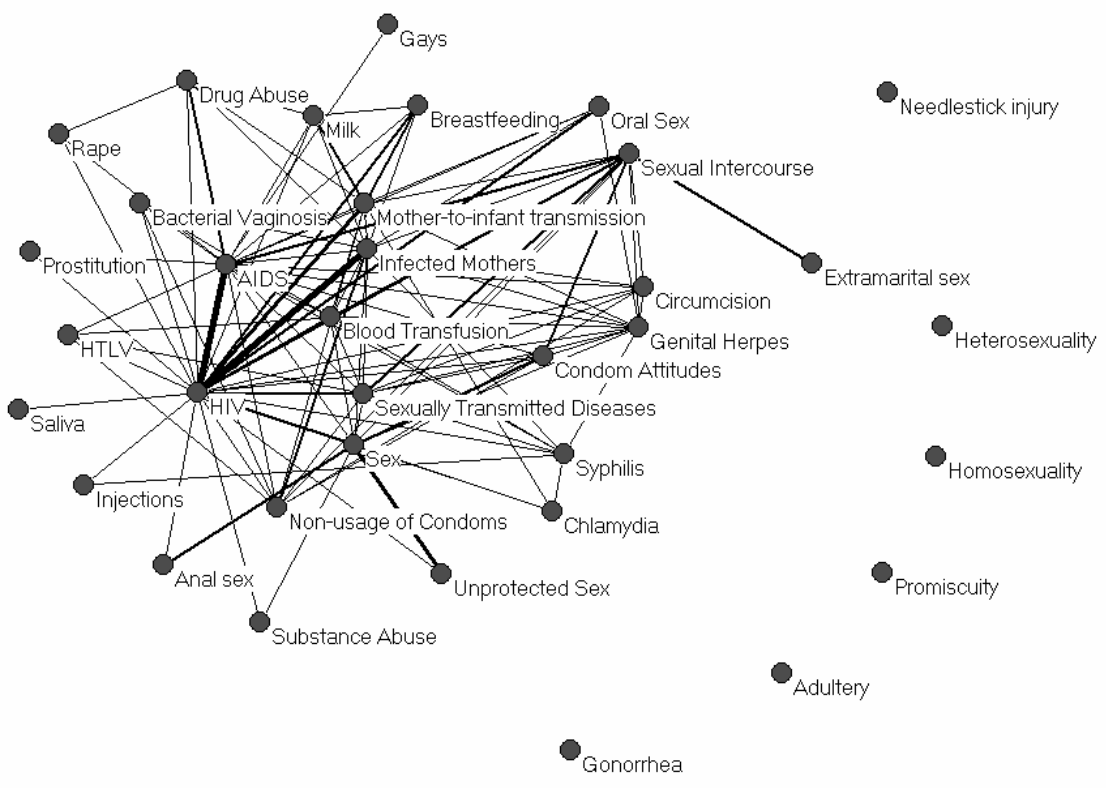

Figure 3. Normalized co-occurrence of HIV/AIDS and risk factors

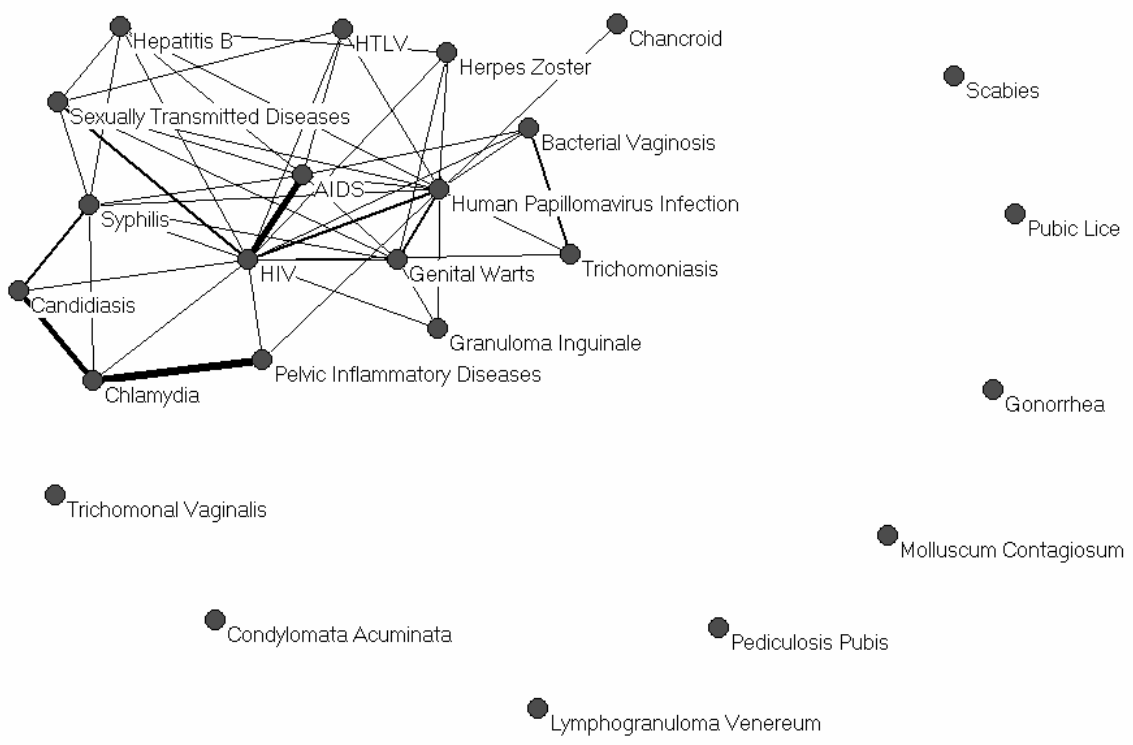

Figure 4. Normalized co-occurrence of HIV/AIDS and other sexually transmitted diseases 
ONYANCHA \& OCHOLLA: Is HIV/AIDS in Africa distinct?

\section{Co-occurrence of HIV/AIDS with other tropical diseases}

Figure 5 provides an analysis of the relationship between HIV/AIDS and other diseases (particularly, tropical diseases) which reveals that a total of 16 titles (or records) contained the words AIDS and Tuberculosis, a relationship that produced a normalized co-occurrence of $\boldsymbol{S}=0.02$, while Hepatitis co-occurred with AIDS in 7 $(\boldsymbol{S}=0.02)$ titles. Other terms that co-occurred with AIDS were Malaria $(6,0.02)$, Meningitis (3, $\boldsymbol{S}=0.02)$, Syphilis (3, $\boldsymbol{S}=0.01)$, Leishmaniasis (2, $\boldsymbol{S}=0.02)$, Sickle Cell (2, $\boldsymbol{S}=0.05$ ), Cholera (1, $\boldsymbol{S}=0.01$ ), and Hypertension (1, $\boldsymbol{S}=0.02)$. HIV had its cooccurrences with 11 terms which comprised Tuberculosis (198, $\boldsymbol{S}=0.17$ ), Malaria (39, $\boldsymbol{S}=0.08$ ), Hepatitis (21, $\boldsymbol{S}=0.04)$, Syphilis (21, $\boldsymbol{S}=0.06)$, Meningitis (15, $\boldsymbol{S}=0.05)$, Malnutrition (5, $\boldsymbol{S}=0.03$ ), Leshmaniasis (4, $\boldsymbol{S}=0.02)$, Schistosomiasis (2, $\boldsymbol{S}=0.01$ ), Cholera (1, $\boldsymbol{S}=0.01$ ), Hypertension (1, $\boldsymbol{S}=0.01$ ), and Polio (1, $\boldsymbol{S}=0.02$ ). No term was found associated with HTLV. Notably, 12 out of 27 terms did not have any linkages, i.e. Amebiasis, Dengue, Ebola, Giardiasis, Hookworm, Jaundice, Lymphatic Filariasis, Oncocerciasis, Trypanosomiasis, Typhoid and Yellow Fever.

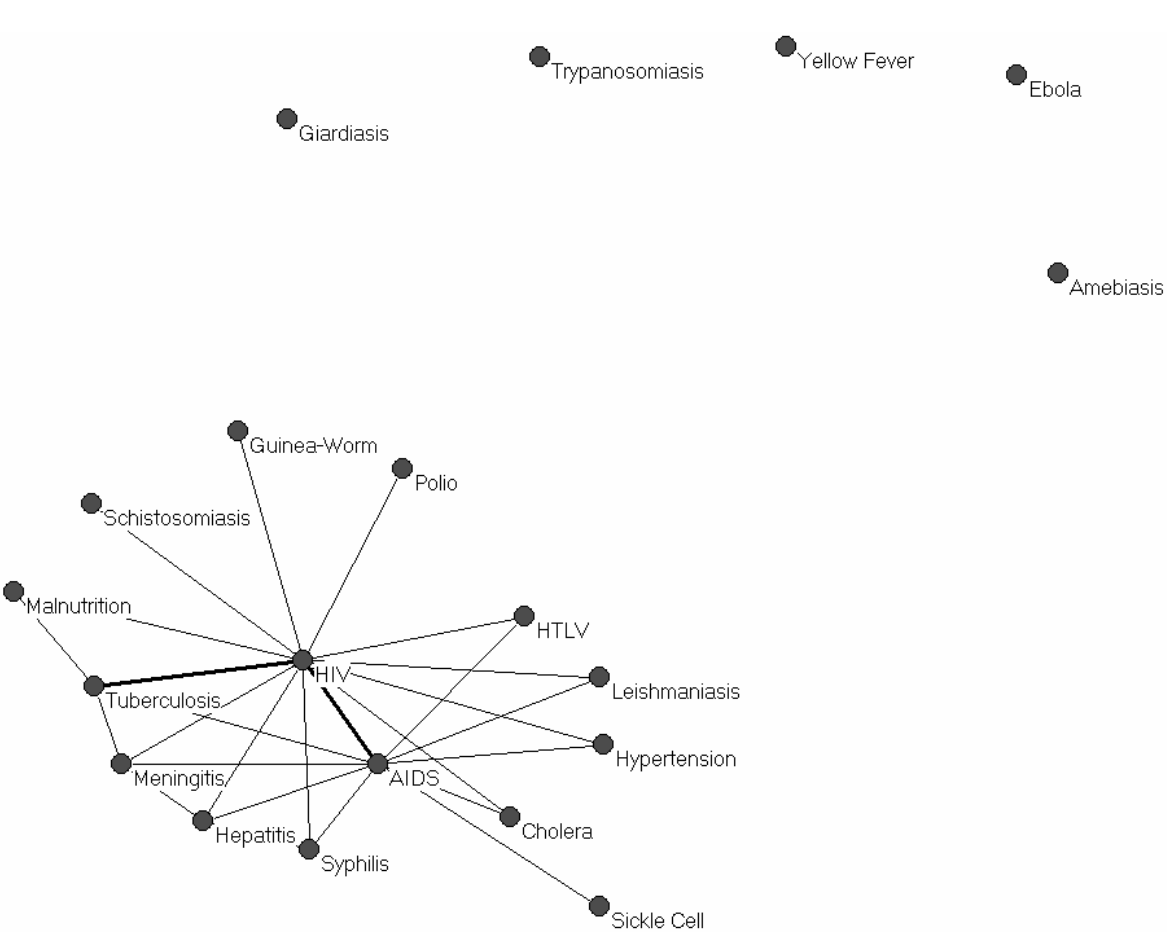

Figure 5. Normalized co-occurrence of HIV/AIDS and other diseases 


\section{Discussion, conclusions and recommendations}

An analysis of HIV/AIDS and the opportunistic diseases (see also Figure 6) produced patterns that could be said to support arguments that some of the opportunistic infections' associations with HIV/AIDS in Africa is stronger than they could be in industrialized nations or any other geographic region (especially when compared to findings in previously conducted studies (e.g. [COHEN, 2000]). Results revealed that HIV/AIDS was associated with 21 opportunistic infections, led by Tuberculosis, followed by Pneumonia, Mycobacterium Avium Complex, Cancer and Kaposi's Sarcoma. Figure 6 clearly shows a huge cluster of the diseases/infections that are closely associated with HIV/AIDS, in the middle of the MDS map. This revelation supports claims that Tuberculosis is the most common ailment in HIV-infected persons in Africa. COHEN [2000] states that Tuberculosis kills more HIV-infected persons in Africa than any other AIDS-related disease. He further notes that the disease is rare in AIDS patients in the United States and Europe, reporting that one neurologist and pathologist found no TB in all 390 autopsies that were performed on people who had died from AIDS. Other opportunistic infections such as Pneumocystis Carinii Pneumonia (PCP) are more common in HIV-infected persons in developed countries. COHEN [2000B] claims that PCP infected more than $80 \%$ of the AIDS patients in developed countries in the 1980 s, while only $8 \%$ of the HIV-infected people autopsied in Africa were found to have had PCP. A few diseases did not have any connection with HIV/AIDS in Africa. These were Toxoplasmosis, Isosporiasis, Encephalopathy, Immunoblastic Lymphoma, and Coccidoidomycosis. Some of the opportunistic infections that were closely associated with HIV/AIDS in this study are missing from the list of the most commonly associated OIs with HIV/AIDS in ONYANCHA \& OCHOLLA's [2005] study, a pattern that perhaps can be attributable to the international nature of that study. Furthermore, ONYANCHA \& OCHOLLA [2005] used subject keywords to conduct a co-word analysis of HIV/AIDS records. The dissimilarity between these two studies might probably also support the view that HIV/AIDS differs from one geographic region to another.

Concerning predisposing factors, the findings illustrated some association between several factors and HIV/AIDS in E\&S Africa as illustrated in section 3.2 and Figure 7. Figure 7 provides two major clusters that are adjacent to each other. The clusters contain closely associated descriptors of HIV/AIDS pre-disposing factors. Their strength of closeness with each other, on the one hand, and HIV/AIDS, on the other, is reflected in the density of the clusters. The cluster at the upper right hand side corner consists of terms that were closely associated with HIV/AIDS while the one that is immediately below it provides terms that did not co-occur with HIV/AIDS. Generally, it was found that the factors that could be influencing the spread of HIV/AIDS in the region include culture, substance or drug abuse, malnutrition, rural-related factors and 
activities, violence, rape, labor migration, ignorance, broken marriages, war, poverty, inequality, socioeconomic factors, refugees and war. Of these, the most influencing factors are rural and drug or substance abuse related, as illustrated by their high frequency and strength of co-occurrence and association with HIV/AIDS. Most of these factors should be subjects of concern in the HIV/AIDS intervention programs. Most of the listed factors are common in Africa and they tend to be associated with marginalization( eg poverty, ignorance, poor health and hygene and proximity to social amenities). Substance and drug abuse was not expected to feuture strongly as an influencing factor in the region.

Another factor that this study considered in investigating the uniqueness of HIV/AIDS in Africa is the co-occurrence of AIDS-related risk factors with HIV/AIDS descriptors within the titles of HIV/AIDS papers. Terms that did not have any cooccurrence with HIV/AIDS were adultery, gonorrhea, heterosexuality, promiscuity, and needlestick injuries. The scatter graph depicted in Figure 8 places these terms far away from the rest of the terms, which recorded high normalized counts. The non-cooccurrence of the aforementioned terms with HIV/AIDS should not be misconstrued, however, to mean that the risk factors are not related to HIV/AIDS. Most likely, the authors used related terms or their variants. Notably, most of the risk factors are sexrelated. Perhaps this is attributable to the fact that HIV/AIDS is mainly contracted through sexual intercourse, especially between different sexes (i.e. largely heterosexually) in the case of Africa, as observed by CoHEN [2000]. Overall, the most common HIV/AIDS-associated risk factors constitute sexual intercourse, vertical transmission (mother to child during birth), blood transfusions and contaminated needles (intravenous drug use, needle stick injuries). According to the findings of this study as shown in Figure 8, several AIDS-related risk factors, including the above, were associated with HIV/AIDS in E\&S Africa. The highest co-occurrence between HIV/AIDS and the risk factors was recorded by "infected mothers", followed closely by a related descriptor, "mother-to-infant transmission". Sexual intercourse and sexually transmitted diseases also ranked highly. The descriptor "Contaminated needles" was less common. It should be noted however that the cluster that describes this pattern (in Figure 8 ) is not as dense as the one that describes the co-occurrence of HIV/AIDS and opportunistic diseases. Figure 8 shows a more dispersed pattern among the descriptors that co-occurred with HIV/AIDS, which implies a loose relationship.

One of the risk factors (and sometimes a pre-disposing factor) is the sexually transmitted diseases. AMUYUNZU-NYAMONGO [2001] argues that individuals with ulcerative sexually transmitted infections (STIs) have an increased risk of transfer of HIV infection by factors of two to four. Of all the sexually transmitted diseases, Papillomavirus Infection was the most common in HIV/AIDS titles. Respectively, it recorded a co-occurrence frequency and strength of association of 144 and $S=0.09$ with $\mathrm{HIV}$, and 13 and $S=0.03$ with AIDS. There were other high co-occurrence frequencies 
from genital warts, hepatitis B, syphilis, bacterial vaginosis, and herpes zoster. Figure 9 provides a scatter graph that describes this pattern of co-occurrence of HIV/AIDS and the other STDs. The non-metric MDS analysis produced two large clusters. The denser one shows the relationship between HIV/AIDS and other STDs while the rest of the terms had little or no co-occurrence at all with HIV/AIDS. Seemingly, HIV/AIDS is mostly associated with un-curable STDs. For instance, the human Papilloma virus is thought to be one of the main causes of cervical cancer and has been linked to other types of cancers of the female reproductive system. While this virus can be treated to reduce signs and symptoms, it does not yet have a cure. Both Herpes and Hepatitis B are other examples of STDs that do not yet have cures. Diseases or viruses that have cures co-occurred less frequently with HIV/AIDS.

The effect of the other diseases on HIV-infected persons was also considered by analyzing the relationship between HIV/AIDS and the selected diseases through termco-occurrence analysis. It has long been observed that HIV/AIDS does not actually kill; rather it is the opportunistic infections/diseases (or other diseases) that kill AIDS patients [MÉDECINS SANS FrontièReS, 2003]. This study sought to identify the most common HIV/AIDS-associated diseases, especially tropical diseases. Out of the total 24 diseases, slightly over one-half $(1 / 2)$ co-occurred with HIV/AIDS as shown in section 3.5. The highest frequency of co-occurrence was recorded by tuberculosis, which is said to be killing more HIV-infected persons in Africa than any other disease [COHEN 2000]. Other terms that were linked to HIV/AIDS descriptors include cholera, guinea-worm, hepatitis, hypertension, leishmaniasis, malaria, malnutrition, meningitis, polio, schistomiasis, sickle cell, and syphilis. Although most of these diseases have no direct link with HIV/AIDS, it is common knowledge that most have an equally (if not greater) negative impact on the economies of E\&S Africa and its peoples. For instance, Malaria is said to be killing millions of people in the region. THE WORLD HEALth ORGANIZATION [2004] estimates that Malaria accounts for more than a million deaths per year, of which about $90 \%$ occur in tropical Africa. Again, it has been observed that HIV infection increases the incidence and severity of clinical Malaria and although the effect of Malaria on HIV is not well documented, UNICEF [2003] states that acute Malaria infection increases viral load. The relatedness of other diseases such as cholera and polio to HIV/AIDS may be attributed to the fact that all are diseases of poverty, which is a common factor in Sub-Saharan Africa. The reasons for the co-occurrence of HIV/AIDS and some of the diseases were, however, not very clear. Perhaps researchers were curious to discover the relationships between these diseases, or simply wanted to find out the impact the diseases have in E\&S Africa.

In conclusion, the following diseases and factors produced high/strong cooccurrence patterns with HIV/AIDS:

- Opportunistic infections: Tuberculosis, Pneumonia, Kaposi's sarcoma, Herpes Simplex, Candidiasis, and Mycobacterium Avium Complex. 
- Pre-disposing factors: Rural-related issues, Drug abuse, Orphans, Gender, and Violence.

- Risk factors: Infected Mothers, Mother-to-infant transmission, Sexual intercourse, Drug abuse, Oral sex, and Breastfeeding

- Sexually transmitted diseases (infections): Human Papillomavirus Infection, Sexually Transmitted Diseases, Genital Warts, Hepatisis B, Syphilis, and Bacterial vaginosis.

- Other diseases: Tuberculosis, Malaria, Hepatitis, Syphilis, and Meningitis.

Worth noting, though, is the fact that the choice of terms used to conduct a co-word analysis in this study largely influenced the patterns of co-occurrence shown and in Figures 6-9. It is possible that some terms (e.g. synonyms, related terms, etc) which were left out may have been used by authors in titling their papers. It is also true that authors' choice of terms when formulating article titles (i.e. research topics) differ from author to author. The analytic approach that was adopted in this study was also limited to only HIV/AIDS articles written by and/or about E\&S Africa. Nevertheless, the data analysis provides partial insight into the uniqueness of HIV/AIDS in Africa.

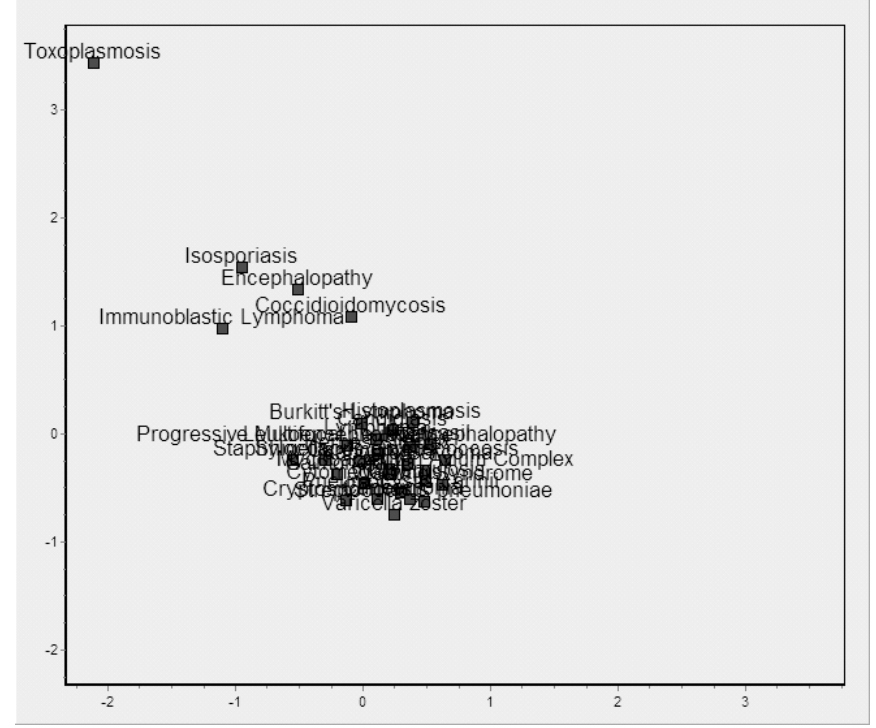

Figure 6. Non-metric MDS mapping of HIV/AIDS and Opportunistic Infections (stress = 0.028) 
ONYANCHA \& OCHOLLA: Is HIV/AIDS in Africa distinct?

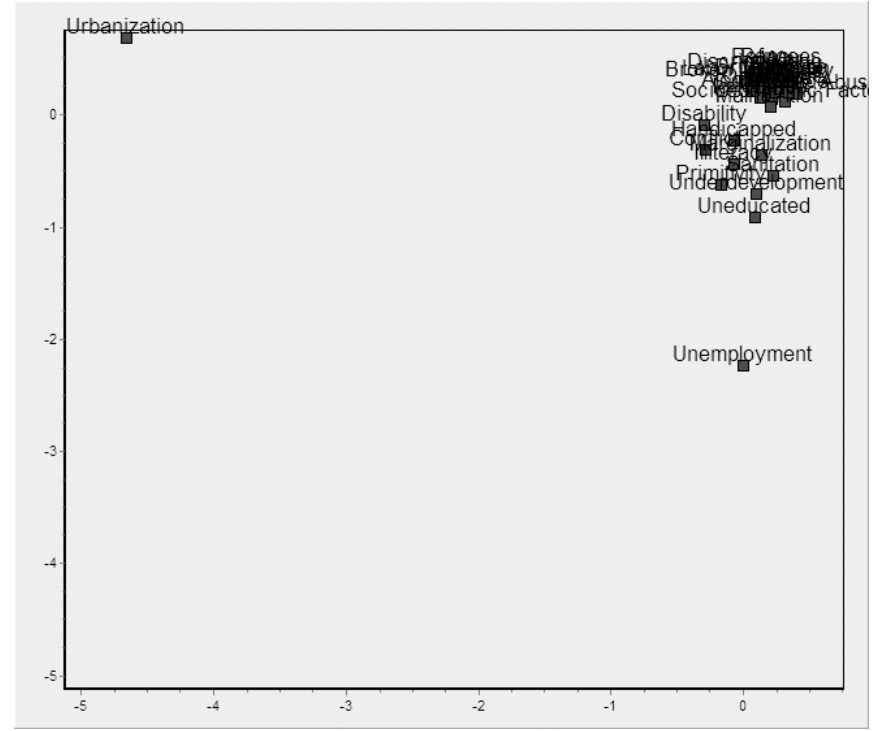

Figure 7. Non-metric MDS mapping of HIV/AIDS and Pre-Disposing factors (stress $=0.008$ )

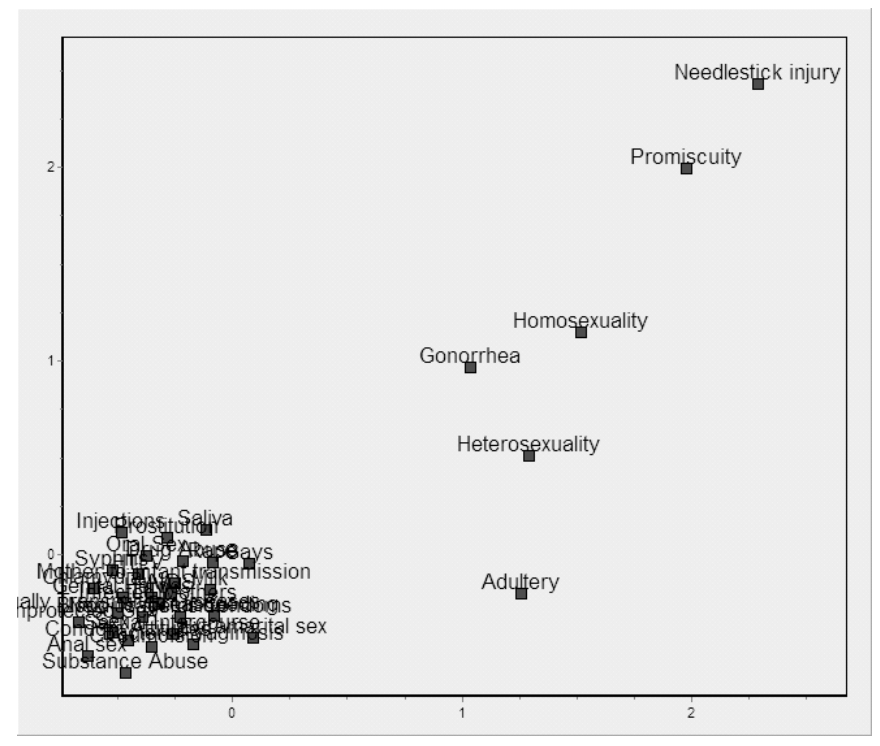

Figure 8. Non-metric MDS mapping of HIV/AIDS and risk factors (stress $=0.024$ ) 
Although it highly probable that HIV/AIDs in Africa is distinct from this study, it is important to caution that the observations made in this study are not conclusive, as it would require a study of the relationship between these terms in other countries (outside Africa) to validate the findings. It is also recommended that a co-word analysis be conducted to check for strengths of association between descriptors of opportunistic diseases, pre-disposing factors, risk factors, sexually transmitted diseases and other diseases, as subject headings, and HIV/AIDS.

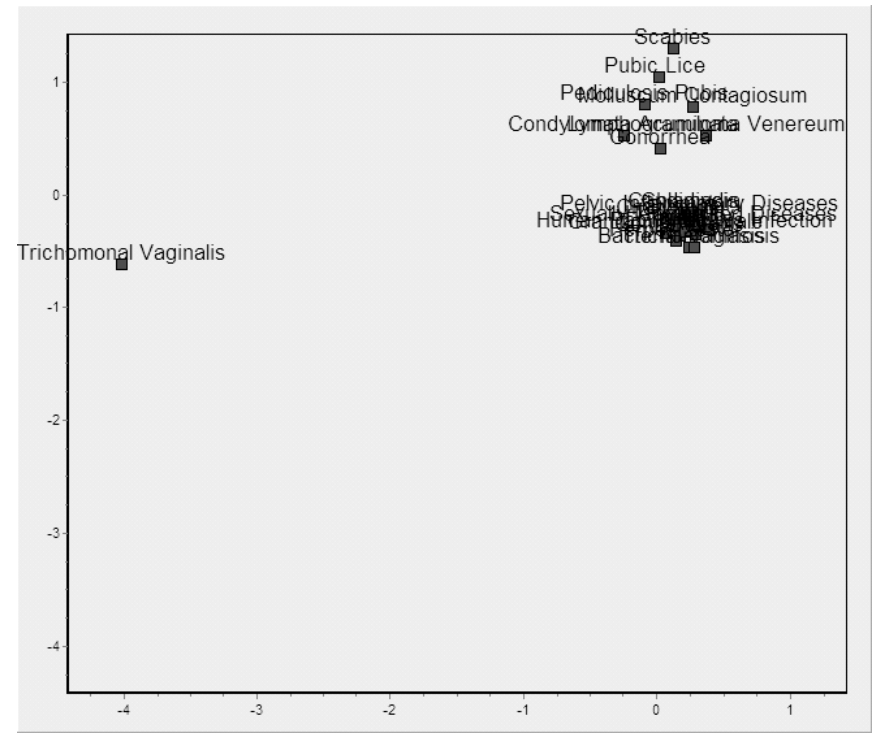

Figure 9. Non-metric MDS mapping of HIV/AIDS and sexually transmitted diseases/infections

The findings can then be compared to the results of this study so as to draw correct conclusions on the uniqueness of HIV/AIDS in Africa. In this way, intervention programs can be drawn to address the most common infections and/or factors that aggravate the AIDS situation in Africa in general, and Eastern and Southern Africa, in particular. Finally, great caution should be taken when drawing conclusions regarding the relationship between various factors/diseases and HIV/AIDS based on the mere cooccurrence of these terms in documents. Although co-word analysis would normally indicate a relationship, the type or nature of such a relationship cannot be immediately discerned. Nevertheless, the patterns witnessed in this study largely agree with the findings and opinions of medical professionals concerning the relationship/influence of certain factors/diseases with/on HIV/AIDS. 
ONYANCHA \& OCHOLLA: Is HIV/AIDS in Africa distinct?

\section{References}

AizawA, A., KageurA, K. (2003), Calculating association between technical terms based on co-occurrences in keyword lists of academic papers. Systems and Computers in Japan, 34 (3) : 85-95.

AMUYUNZU-NyAmongo, M. (2001), HIV/AIDS in Kenya: Moving beyond policy and rhetoric. [Online]. African Sociological Review, 5 (2).

Baldwin, C., Hughes, J., Hope, T., Jacoby, R., Ziebland, S. (2003), Ethics and dementia: Mapping the literature by bibliometric analysis. International Journal of Geriatric Psychiatry, 18 : 41-54.

Bookstein, A., RaitA, T. (2001), Discovering term occurrence structure in text. Journal of the American Society for Information Science, 52 (6) : 476-486.

Bookstein, A., Kulyukin, V., Raita, T., Nicholson, J. (2003), Adapting measures of clumping strength assess term-term similarity. Journal of the American Society for Library Science and Technology, $54(7): 611-620$.

Borgatti, S. P., Everett, M. G., Freeman, L. C. (2002), Ucinet 6 for Windows. Harvard: Analytic Technologies.

Callon, M., Courtial, J.-P., Laville, F. (1991), Co-word analysis as a tool for describing the network of interactions between basic and technological research: The case of polymer chemistry. Scientometrics, 22 (1) : 153-203.

Callon, M., Law, J., RIP. A. (1986), Mapping of the Dynamics of Science and Technology. London: MacMillan.

CoHEN, J. (2000B), Is AIDS in Africa a distinct disease? Science, 288 (5474) : 2153-2155.

Conlon, C. P., SNydman, D. R. (2004), Mosby's Color Atlas and Text of Infectious Diseases. Edinburgh: Mosby.

COUlter, N., MonARCH, I., KondA, S. (1998), Software engineering as seen through its research literature: a study in co-word analysis. Journal of the American Society for Information Science, 49 (13) : 1206-1223.

Courtial, J.-P. (1994), A co-word analysis of scientometrics. Scientometrics, 31 (3) : 251-260.

Courtial, J.-P., LAW, J. (1989), A co-word study of artificial intelligence. Social Studies in Science, $19: 301-311$.

Ding, Y., Chowdhury, G. G, Foo, S. (2001), Bibliometric cartography of information retrieval research by using co-word analysis. Information Processing and Management, 37 : 817-842.

HuI, S. C., Fong, A. C. M. (2004), Document retrieval from a citation database using conceptual clustering and co-word analysis. Online Information Review, 28 (1) : 22-32.

JACOBS, N. (2002), Co-term network analysis as a means of describing the informational landscapes of knowledge communities across sectors. Journal of Documentation, 58 (5) : 548-562.

KopCSA, A., SCHIEBEL, E. (1998), Science and technology mapping: A new iteration model for representing multidimensional relationships. Journal of the American Society for Information Science, 49 (1) : 7-17.

Kostoff, R. N. (2001), Science and Technology Metrics. Retrieved April 11, 2002, from Defence Technical Information Center. Information for the Defence Community Website http://www.dtic.mil/dtic/kostoff/Metweb5_IV.htm

KRSUL, I. (2002), Co-word analysis tool. Retrieved on December $3^{\mathrm{d}}$, 2003, from http://www.acis.ufl.edu/ ivan/coword/algorithmdescription.pdf

LAW, J., WhitTAKeR, J. (1992), Mapping acidification research: A test of the co-word method. Scientometrics, 23 (3) : 417-461.

LEYDESDORFF, L. (1988), Words and co-words as indicators of intellectual organization. Research Policy, $18: 209-223$.

LEYDESDORFF, L. (2004), FullText.exe for Full text analysis. Retrieved June 18, 2006, from http://www.leydesdorff.net

MÉDECINS SANS FRONTIÈRES (MSF) (2003), HIV/AIDS. Retrieved July 18, 2005, from http://www.accessmed-msf.org/campaign/hiv01.shtm

NordBerg, E. (Ed.) (2001), Communicable Diseases: A Manual for Health Workers in Sub-Saharan Africa. Nairobi: African Medical and Research Foundation. 
ONYANCHA \& OCHOLLA: Is HIV/AIDS in Africa distinct?

ONYANCHA, O. B., OCHOLla, D. N. (2005), An informetric investigation of the relatedness of opportunistic infection to HIV/AIDS. Information Processing and Management, 41 : 1573-1588.

SCHNEIDER, J. W., BORLUND, P. (2004), Introduction to bibliometrics for construction and maintenance of thesauri: Methodical considerations. Journal of Documentaion, 60 (5) : 524-549.

Turner, W., Chartron, G., Laville, F., Michelet, B. (1988), Packaging information for peer review: New co-word analysis techniques. In A. VAN RAAN (Ed.), Handbook of Quantitative Studies of Science And Technology, 291-323. Amsterdam: North Holland.

United NATIONS InTERnAtionAl ChILDRENS Fund (UNICEF), (2003), Malaria and HIV/AIDS. Retrieved July 25, 2006, from http://www.unicef.org/health/files/UNICEFTechnicalNote6MalariaandHIV.doc

VAUGHAN, L., YOU, J. (2006), Comparing business competition based on Web co-link data: the global market vs. the Chinese market. Scientometrics, $3: 611-628$.

WhitTAKer, J. (1989), Creativity and conformity in science: Titles, keywords, and co-word analysis. Social Science in Science, 19 : 473-496.

World HeAlth ORgANIZATION (2004), Malaria and HIV/AIDS interactions and implications: Conclusions of a technical consultation convened by WHO, June 23-25. Retrieved July 25, 2006 from http://www.who.int/hiv/pub/prev_care/en/WHO\%20Malaria\%20and\%20AIDS.pdf

YitzHAKI, M. (2001), Relation of title length of journal article to length of article. In: M. DAVIS, C. S. WILSON (Eds), Proceedings of the 8th International Conference on Scientometrics and Informetrics, Sydney, July, 16-20, 2 : 759-769. 
Appendix A

List of terms used to conduct co-word analysis of HIV/AIDS literature

\begin{tabular}{|c|c|}
\hline \multicolumn{2}{|r|}{ Opportunistic Infections } \\
\hline Burkitt's Lymphoma & Leukoencephalopathy \\
\hline Cancer & Lymphoma \\
\hline Candidiasis & Mycobacterium Avium Complex \\
\hline Carcinoma & Pneumocystis carinii \\
\hline Coccidioidomycosis & Pneumonia \\
\hline Cryptococcosis & Progressive Multifocal Leukoencephalopathy \\
\hline Cryptosporidiosis & Salmonella \\
\hline Cytomegalovirus & Shigella \\
\hline Encephalopathy & Staphylococcus aureus \\
\hline Herpes Simplex & Streptococcus pneumoniae \\
\hline Histoplasmosis & Toxoplasmosis \\
\hline Immunoblastic Lymphoma & Tuberculosis \\
\hline Isosporiasis & Varicella zoster \\
\hline Kansasii & Wasting Syndrome \\
\hline \multicolumn{2}{|l|}{ Kaposi's Sarcoma } \\
\hline \multicolumn{2}{|r|}{ Pre-Disposing Factors } \\
\hline Alcoholism & Orphans \\
\hline Broken Marriage & Poverty \\
\hline Conflict & Primitivity \\
\hline Culture & Rape \\
\hline Disability & Refugees \\
\hline Discrimination & Rural \\
\hline Drug Abuse & Sanitation \\
\hline Gender & Socioeconomic Factors \\
\hline Handicapped & Substance Abuse \\
\hline Ignorance & Underdevelopment \\
\hline Illiteracy & Uneducated \\
\hline Inequality & Unemployment \\
\hline Labor Migration & Urbanization \\
\hline Marginalization & Violence \\
\hline Malnutrition & War \\
\hline \multicolumn{2}{|r|}{ Risk Factors } \\
\hline Adultery & Infected Mothers \\
\hline Anal Sex & Milk \\
\hline Bacterial Vaginosis & Mother-to-infant transmission \\
\hline Blood Transfusion & Needlestick injury \\
\hline Breastfeeding & Non-usage of Condoms \\
\hline Chlamydia & Oral Sex \\
\hline Circumcision & Promiscuity \\
\hline Condom Attitudes & Prostitution \\
\hline Drug Abuse & Rape \\
\hline Extramarital sex & Saliva \\
\hline Gays & Sex \\
\hline Genital Herpes & Sexual Intercourse \\
\hline Gonorrhea & Sexually Transmitted Diseases \\
\hline Heterosexuality & Substance Abuse \\
\hline Homosexuality & Syphilis \\
\hline Injections & Unprotected Sex \\
\hline
\end{tabular}


ONYANCHA \& OCHOLLA: Is HIV/AIDS in Africa distinct?

Sexually Transmitted Diseases

\begin{tabular}{ll} 
Bacterial Vaginosis & Lymphogranuloma Venereum \\
Candidiasis & Molluscum Contagiosum \\
Chancroid & Pediculosis Pubis \\
Chlamydia & Pelvic Inflammatory Diseases \\
Condylomata Acuminata & Pubic Lice \\
Genital Warts & Scabies \\
Gonorrhea & Sexually Transmitted Diseases \\
Granuloma Inguinale & Syphilis \\
Hepatitis B & Trichomonal Vaginalis \\
Herpes Zoster & Trichomoniasis \\
Human Papillomavirus Infection & \\
\hline
\end{tabular}

Other Diseases (mainly tropical diseases)

\begin{tabular}{ll} 
Amebiasis & Malaria \\
Cholera & Malnutrition \\
Dengue & Meningitis \\
Ebola & Onchocerciasis \\
Giardiasis & Polio \\
Guinea-Worm & Schistosomiasis \\
Hepatitis & Sickle Cell \\
Hookworm & Syphilis \\
Hypertension & Trypanosomiasis \\
Jaundice & Tuberculosis \\
Leishmaniasis & Typhoid \\
Lymphatic Filariasis & Yellow Fever \\
\hline
\end{tabular}

